\title{
Real-world experience of afatinib as first-line therapy for advanced EGFR mutation-positive non-small cell lung cancer in Korea
}

\author{
Sung Yong Lee ${ }^{1 \#}$, Chang-Min Choi ${ }^{2 \#}$, Yoon Soo Chang ${ }^{3}$, Kye Young Lee ${ }^{4}$, Seung Joon Kim ${ }^{5}$, \\ Sei Hoon Yang ${ }^{6}$, Jeong Seon Ryu ${ }^{7}$, Jeong Eun Lee ${ }^{8}$, Shin Yup Lee ${ }^{9}$, Ji Young Park ${ }^{10}$, Young-Chul Kim ${ }^{11}$, \\ In-Jae Oh ${ }^{11}$, Chi Young Jung ${ }^{12}$, Sang Hoon Lee ${ }^{13}$, Seong Hoon Yoon ${ }^{14}$, Juwhan Choi ${ }^{1}$, Tae Won Jang ${ }^{15}$ \\ ${ }^{1}$ Korea University Guro Hospital, Seoul, South Korea; ${ }^{2}$ Ulsan University Asan Medical Center, Seoul, South Korea; ${ }^{3}$ Yonsei University Gangnam \\ Severance Hospital, Seoul, South Korea; ${ }^{4}$ Konkuk University Medical Center, Seoul, South Korea; ${ }^{5}$ Catholic University Seoul St. Mary's Hospital, \\ Seoul, South Korea; ${ }^{6}$ Wonkwang University Hospital, Iksan, South Korea; ${ }^{7}$ Inha University Hospital, Incheon, South Korea; ${ }^{8}$ Chungnam National \\ University, Daejeon, South Korea; ${ }^{9}$ Kyungpook National University Chilgok Hospital, Daegu, South Korea; ${ }^{10}$ Hallym University Sacred Heart \\ Hospital, Anyang, South Korea; ${ }^{11}$ Chonnam National University Medical School and Hwasun Hospital, Hwasun, South Korea; ${ }^{12}$ Daegu Catholic \\ University Medical Center, Daegu, South Korea; ${ }^{13}$ Yonsei University Severance Hospital, Seoul, South Korea; ${ }^{14}$ Pusan National University Yangsan \\ Hospital, Yangsan, South Korea; ${ }^{15}$ Kosin University Gospel Hospital, Busan, South Korea \\ Contributions: (I) Conception and design: YS Chang, JS Ryu, SY Lee, JY Park, CY Jung, SH Lee, SH Yoon, J Choi, TW Jang; (II) Administrative \\ support: CM Choi, KY Lee, J Choi, TW Jang; (III) Provision of study materials or patients: CM Choi, YS Chang, KY Lee, YC Kim, CY Jung, \\ SH Yoon, TW Jang; (IV) Collection and assembly of data: CM Choi, KY Lee, JS Ryu, JY Park, J Choi, TW Jang; (V) Data analysis and \\ interpretation: SY Lee, CM Choi, KY Lee, SJ Kim, SH Yang, JS Ryu, JE Lee, SY Lee, JY Park, IJ Oh, CY Jung, SH Lee, SH Yoon, J Choi, \\ TW Jang; (VI) Manuscript writing: All authors; (VII) Final approval of manuscript: All authors. \\ \#These authors contributed equally to this work. \\ Correspondence to: Tae Won Jang, MD, PhD. Department of Internal Medicine, Kosin University Gospel Hospital, Busan, South Korea. \\ Email: jangtw22@hanmail.net.
}

Background: We investigated the clinical characteristics and treatment outcomes of Korean patients receiving first-line afatinib for advanced epidermal growth factor receptor mutation-positive $\left(E G F R \mathrm{~m}^{+}\right)$nonsmall cell lung cancer (NSCLC) in a real-world setting.

Methods: Electronic case reports were retrospectively reviewed from patients across 15 sites in South Korea. Outcome measures included baseline characteristics, overall response rate (ORR), time-totreatment discontinuation (TTD), and overall survival (OS). Subgroups were: presence/absence of brain metastases at baseline, dose reductions, and baseline EGFR mutation category.

Results: Among 422 patients, 39.8\% had brain metastases and 59.0\%/25.1\%/10.0\%/5.0\% had Del19/ L858R/compound/uncommon EGFR mutations at baseline. ORR was $62.6 \%$ overall; responses were observed across all EGFR mutation categories, including against compound mutations. Median TTD was 17.8 months; median OS was not reached (NR). Median TTD and OS were longer in patients without versus with brain metastases (TTD: 22.9 vs. 14.8 months, $\mathrm{P}=0.001$; OS: NR vs. 40.3 months, $\mathrm{P}=0.0009$ ) and patients with versus without dose reductions (TTD: 22.2 vs. 14.2 months, $\mathrm{P}=0.0004$; OS: NR vs. 40.3 months, $\mathrm{P}=0.0117$ ). Median OS was 30.5/37.7 months in patients receiving chemotherapy/osimertinib as subsequent therapy. The most common treatment-related adverse events (TRAEs; any grade/grade $\geq 3$ ) were diarrhea $(31.3 \% / 8.5 \%)$ and rash (23.0\%/8.1\%). Overall, 34 patients (8.1\%) discontinued afatinib due to AEs.

Conclusions: Afatinib was well tolerated with no new safety signals, and efficacy was encouraging in Korean patients with EGFRm ${ }^{+}$NSCLC, including those with baseline brain metastases and/or uncommon EGFR mutations. AE management with dose reductions facilitated a long TTD, prolonging the chemotherapy-free period for many patients. 


\begin{abstract}
Keywords: Afatinib; epidermal growth factor receptor (EGFR); first-line; non-small cell lung cancer (NSCLC);
\end{abstract} real-world

Submitted Jul 07, 2021. Accepted for publication Nov 11, 2021.

doi: $10.21037 /$ tlcr-21-501

View this article at: https://dx.doi.org/10.21037/tlcr-21-501

\section{Introduction}

Lung cancer is the most common cause of cancer-related mortality worldwide (1), and in South Korea, where it is expected to account for approximately 18,796 deaths in 2020 (2). Activating mutations in the epidermal growth factor receptor (EGFR) gene, which lead to dysregulated EGFR signaling, are observed in up to $50 \%$ of Asian patients with non-small cell lung cancer (NSCLC) $(3,4)$. EGFR-mutated tumors tend to be dependent on EGFR activity, rendering them highly sensitive to targeted inhibition with EGFR tyrosine kinase inhibitors (TKIs) (5). Accordingly, EGFR TKIs are now the first-line treatment of choice for patients with EGFR mutation-positive $\left(E G F R \mathrm{~m}^{+}\right)$NSCLC, and five such agents are currently approved in this setting. These are: the first-generation reversible EGFR TKIs, gefitinib and erlotinib; the secondgeneration irreversible ErbB family blockers, afatinib and dacomitinib; and the third-generation irreversible, wildtype sparing EGFR TKI, osimertinib (6).

Afatinib is an ErbB family blocker that irreversibly inhibits EGFR, human epidermal growth factor receptor (HER)2 and HER4, and blocks transphosphorylation of HER3, thereby blocking signaling via all ErbB family homo- and hetero-dimers $(7,8)$. In randomized clinical trials, afatinib demonstrated superior efficacy as first-line treatment versus chemotherapy (LUX-Lung 3 and 6) and gefitinib (LUX-Lung 7) in patients with EGFRm ${ }^{+}$NSCLC (9-11). Across these trials, afatinib was well tolerated, with few treatment discontinuations due to adverse events (AEs). Treatment-related AEs (TRAEs) with afatinib were predominantly class-related gastrointestinal and skinrelated toxicities, and these were managed effectively with tolerability-guided dose reductions (9-11).

As well as being highly active against common (Del19 and L858R) EGFR mutations, afatinib shows a broad preclinical and clinical inhibitory profile against many uncommon EGFR mutations, including those occurring in combination with an independent common or uncommon mutation (known as 'compound mutations') $(12,13)$.
Afatinib is clinically active against the most prevalent uncommon mutations, G719X, S768I, and L861Q, in exons 18,20 , and 21 , respectively (14), and is approved in many countries for the treatment of NSCLC harboring these activating mutations, as well as for Del19-/L858R-positive NSCLC. In South Korea, afatinib has been approved and reimbursed in this indication since 2014. Evidence also suggests that afatinib can also effectively penetrate the blood-brain barrier, and that it may be effective both in treating existing central nervous system (CNS) metastases and in mitigating the risk of CNS progression (15).

Randomized controlled trials such as the LUX-Lung studies demonstrate the efficacy and safety of study drugs under highly controlled settings, often with strict inclusion criteria. Therefore, it is important to evaluate the efficacy and tolerability of afatinib in real-world studies in broader patient populations, which may better reflect daily clinical practice (16). Real-world data can be used to assess treatment effectiveness in patient populations that are generally under-represented in clinical trials, such as elderly patients, patients with brain metastases, patients with uncommon EGFR mutations, and those with comorbidities. Furthermore, clinical trials often have strict discontinuation and stopping criteria, whereas in the real-world setting, treatment may continue beyond radiological progression. So far, available real-world evidence suggests that afatinib is tolerable and effective in diverse patient populations in everyday clinical practice. Several real-world comparative studies also indicate that afatinib is associated with improved efficacy compared with first-generation EGFR TKIs, consistent with the results of LUX-Lung 7 (17). For example, in a recent single-center analysis of 467 patients treated with first-line EGFR TKIs in South Korea, median progression-free survival (PFS) was significantly longer with afatinib versus gefitinib or erlotinib, and the PFS benefit with afatinib was particularly pronounced in subgroups with Del19 or uncommon EGFR mutations (18).

In this study, we investigate the clinical characteristics and treatment courses of patients who received afatinib as first-line therapy for advanced $E G F R \mathrm{~m}^{+} \mathrm{NSCLC}$ in the 
real-world setting in South Korea. We present the following article in accordance with the STROBE reporting checklist (available at https://dx.doi.org/10.21037/tlcr-21-501).

\section{Methods}

\section{Patients and study design}

This was a retrospective, multicenter cohort study of patients with advanced EGFRm ${ }^{+}$NSCLC enrolled in the Korean Academy of Tuberculosis and Respiratory Disease (KATRD) EGFR cohort. A total of 15 sites across South Korea participated in patient registration.

Electronic case report forms from patients treated with first-line afatinib in real-world practice were retrospectively reviewed. To reduce bias, a contract research organization (CRO) conducted data management and researchers were not involved. Eligible patients were aged $>20$ years, with EGFRm ${ }^{+}$TKI-naïve, locally advanced or metastatic NSCLC, who had started on first-line afatinib between April 2007 and December 2018. Patients were required to have absolute neutrophil count $\geq 1,500 / \mathrm{mm}^{3}$, platelet count $\geq 100,000 / \mathrm{mm}^{3}$, hemoglobin $\geq 9 \mathrm{~g} / \mathrm{dL}$, total bilirubin $\leq 1.25 \times$ upper limit of normal (ULN), aspartate aminotransferase and alanine aminotransferase $\leq 3.0 \times \mathrm{ULN}$, alkaline phosphatase $\leq 2.5 \times$ ULN and serum creatinine $\leq 1.5 \mathrm{mg} / \mathrm{dL}$. Patients with histologically confirmed smallcell lung cancer or other metastatic tumors were excluded.

The objectives were to assess the clinical characteristics and treatment outcomes of patients who received afatinib as a first-line therapy in the real-world setting.

\section{Outcomes and assessments}

Outcome measures included: patient baseline characteristics; objective response [complete response (CR) or partial response (PR)]; disease control [CR, PR, or stable disease (SD)]; time-to-treatment discontinuation (TTD), defined as the time from the first dose of afatinib to the date of treatment discontinuation or death; overall survival (OS), defined as the time from the first dose of afatinib until death; and subsequent treatments. Afatinib dose reductions and treatment switches were also documented. AEs and TRAEs were graded by the National Cancer Institute's Common Terminology Criteria for Adverse Events version 4.03.

Clinical subgroups were defined based on: presence or absence of brain metastases at baseline, afatinib dose reductions, and baseline EGFR mutation type/location. Sites were requested to provide information on mutational status at initial and second biopsy (performed upon disease progression), if available. EGFR mutation and T790M status were determined as per local methodology and practice, using direct sequencing, peptide nucleic acid (PNA)-clamp, or other methods.

\section{Statistical analysis}

Baseline characteristics, tumor responses, AEs, and dose modifications were descriptive. Kaplan-Meier methodology was used to determine the median TTD and median OS, and a log-rank test and Cox proportional hazards model were used to compare groups. For patients still on treatment, TTD and OS was censored at data cut-off (April 4, 2019). The CRO requested a query from the researcher to minimize missing data. Statistical analyses were performed by using SAS version 9.4. A P value of $<0.05$ was considered statistically significant.

\section{Ethical statement}

The study was conducted in accordance with the guidelines of the Helsinki Declaration (as revised in 2013). The study was approved by the institutional ethics review boards of: Korea University Guro Hospital (2018GR0013), Asan Medical Center (2018-0012), Yonsei University Gangnam Severance Hospital (3-2020-0003), Konkuk University Medical Center (KUH1010909), Catholic University Seoul St. Mary's Hospital (KC20RCDI0129), Wonkwang University Hospital (WKUH-201606-HR-058), Inha University Hospital Institutional Review Board (2020-01-016), Chungnam National University Institutional Review Board (CNUH 2020-02-022-006), Kyungpook National University Chilgok Hospital Institutional Review Board (KNUCH 2020-01-010), Hallym University Sacred Heart Hospital Institutional Review Board (HALLYM 2020-07-041), Chonnam National University Hwasun Hospital Institutional Review Board (CNUHH-2017-179), Daegu Catholic University Medical Center Institutional Review Board (CR-18-097), Institutional Review Board of Severance Hospital (4-2019-1214), Pusan National University Yangsan Hospital Institutional Review Board (05-2020-006), and Kosin University Gospel Hospital Institutional Review Board (KUGH 2017-11-030). Individual consent for this retrospective analysis was waived. 


\section{Results}

\section{Patients and treatment}

In total, 422 patients treated with first-line afatinib were included in the analysis. Baseline demographics and disease characteristics are summarized in Table 1 . Overall, $54.3 \%$ of patients were male, $52.1 \%$ had never smoked, $95.3 \%$ had adenocarcinoma, and $82.9 \%$ received the approved $40 \mathrm{mg}$ starting dose of afatinib.

The method of EGFR mutation detection at initial biopsy was recorded for 356 patients. The most commonly used method was PNA-clamp [n=326 (91.6\%)], followed by direct sequencing [n=80 (22.5\%]], or other methods [n=5 (1.4\%)]. For some patient samples, both PNA-clamp and direct sequencing were performed. Initial biopsy was performed most commonly using tissue samples $[\mathrm{n}=381(90.3 \%)]$, followed by pleural effusion samples [n=15 (3.6\%)].

At the start of afatinib treatment, $249(59.0 \%)$ patients had tumors harboring a Del19 mutation and 106 (25.1\%) had L858R-positive tumors; the remaining patients had NSCLC with compound mutations $[\mathrm{n}=42(10.0 \%)]$, uncommon mutations only [ $\mathrm{n}=21(5.0 \%)]$, unknown status [n=3 (0.7\%)], or de novo T790M mutation only [1 (0.2\%)]. Eight $(1.9 \%)$ patients had tumors harboring a T790M mutation at initial biopsy (de novo + compound mutations). Of these, seven patients had compound mutations: three patients also had Del19-positive tumors, two patients had L858R-positive tumors, and two patients had tumors with a G719X mutation. In total, 168 (39.8\%) patients had brain metastases at baseline, and among the 145 patients with available data, $60(41.5 \%)$ were treated with afatinib only (i.e., received no brain surgery or radiotherapy), 51 patients (35.2\%) underwent whole-brain radiotherapy, 21 patients $(14.5 \%)$ had gamma-knife radiosurgery, and the remaining 13 patients $(9.0 \%)$ received other treatments for baseline brain metastases.

At the time of analysis, $273(64.7 \%)$ patients had discontinued afatinib, and 149 (35.3\%) remained on treatment. The most common reasons for discontinuation were progressive disease $[\mathrm{n}=171(62.6 \%)]$, toxicity $[\mathrm{n}=34$ $(12.5 \%)]$, and loss to follow-up [ $\mathrm{n}=30(11.0 \%)]$.

\section{Tumor response}

Across all response-evaluable patients $(\mathrm{n}=366)$, six patients
Table 1 Baseline demographics and clinical characteristics

\begin{tabular}{|c|c|}
\hline Characteristic & $\begin{array}{l}\text { KATRD EGFR cohort } \\
(\mathrm{n}=422)\end{array}$ \\
\hline Mean age, years (standard deviation) & $63.8(10.9)$ \\
\hline Male, n (\%) & $229(54.3)$ \\
\hline \multicolumn{2}{|l|}{ Smoking history, $\mathrm{n}(\%)$} \\
\hline Never smoked & $220(52.1)$ \\
\hline Ex-smoker & $120(28.4)$ \\
\hline Current smoker & $61(14.5)$ \\
\hline Unknown & $21(5.0)$ \\
\hline \multicolumn{2}{|l|}{ Tumor histology, n (\%) } \\
\hline Adenocarcinoma & $402(95.3)$ \\
\hline Squamous cell carcinoma & $8(1.9)$ \\
\hline Adenosquamous carcinoma & $5(1.2)$ \\
\hline NSCLC not otherwise specified & $3(0.7)$ \\
\hline Sarcomatoid carcinoma & $1(0.2)$ \\
\hline Other & $2(0.5)$ \\
\hline Unknown & $1(0.2)$ \\
\hline \multicolumn{2}{|l|}{ Stage, n (\%) } \\
\hline $\mid \mathrm{lb}-\mathrm{IIIb}$ & $25(5.9)$ \\
\hline IIIc & $2(0.5)$ \\
\hline IVa & $187(44.3)$ \\
\hline $\mathrm{IVb}$ & $201(47.6)$ \\
\hline Unknown & $7(1.7)$ \\
\hline \multicolumn{2}{|l|}{ Location of M1 sites at diagnosis ${ }^{\mathrm{a}}, \mathrm{n}(\%)$} \\
\hline Lung/pericardium/pleura & $270(64.0)$ \\
\hline Brain/leptomeningeal & $182(43.1)$ \\
\hline Bone & $169(40.0)$ \\
\hline Liver & $41(9.7)$ \\
\hline Adrenal & $28(6.6)$ \\
\hline Other & $27(6.4)$ \\
\hline Unknown & $38(9.0)$ \\
\hline \multicolumn{2}{|l|}{ Brain metastases at diagnosis, $\mathrm{n}(\%)$} \\
\hline Present & $168(39.8)$ \\
\hline Not present & $249(59.0)$ \\
\hline Unknown & $5(1.2)$ \\
\hline
\end{tabular}

Table 1 (continued) 
Table 1 (continued)

\begin{tabular}{|c|c|}
\hline Characteristic & $\begin{array}{c}\text { KATRD EGFR cohort } \\
(\mathrm{n}=422)\end{array}$ \\
\hline \multicolumn{2}{|c|}{ MRI/CT scan undertaken at baseline, $\mathrm{n}(\%)$} \\
\hline Yes & $389(92.2)$ \\
\hline No & $18(4.3)$ \\
\hline Unknown & $15(3.6)$ \\
\hline \multicolumn{2}{|l|}{ EGFR mutation type ${ }^{\mathrm{b}}, \mathrm{n}(\%)$} \\
\hline \multicolumn{2}{|l|}{ Common } \\
\hline Del19 & $249(59.0)$ \\
\hline L858R & $106(25.1)$ \\
\hline Compound & $42(10.0)$ \\
\hline Uncommon & $21(5.0)$ \\
\hline de novo T790M & $1(0.2)$ \\
\hline Unknown & $3(0.7)$ \\
\hline \multicolumn{2}{|l|}{ EGFR mutation location ${ }^{\mathrm{c}}, \mathrm{n}(\%)$} \\
\hline Exon 18 & $22(5.2)$ \\
\hline Exon 19 & $258(61.1)$ \\
\hline Exon 20 & $18(4.3)$ \\
\hline Exon 21 & $140(33.2)$ \\
\hline Unknown & $2(0.5)$ \\
\hline EGFR mutation location ${ }^{\mathrm{b}}, \mathrm{n}(\%)$ & $n=420$ \\
\hline Exon 18 & $11(2.6)$ \\
\hline Exon $18+$ Exon 19 & $1(0.2)$ \\
\hline Exon 18 + Exon 20 & $5(1.2)$ \\
\hline Exon 18 + Exon 21 & $5(1.2)$ \\
\hline Exon 19 & $253(60.2)$ \\
\hline Exon $19+$ Exon 20 & $4(0.9)$ \\
\hline Exon 20 & $5(1.2)$ \\
\hline Exon $20+$ Exon 21 & $3(0.7)$ \\
\hline Exon 21 & $130(30.1)$ \\
\hline Unknown & $3(0.7)$ \\
\hline \multirow[t]{2}{*}{ ALK mutation, $\mathrm{n}(\%)$} & $\mathrm{n}=184$ \\
\hline & $8(4.3)$ \\
\hline \multirow[t]{2}{*}{ KRAS mutation, n (\%) } & $\mathrm{n}=25$ \\
\hline & $0(0)$ \\
\hline Afatinib starting dose, $\mathrm{n}(\%)$ & \\
\hline
\end{tabular}

Table 1 (continued)
Table 1 (continued)

\begin{tabular}{lc}
\hline Characteristic & $\begin{array}{c}\text { KATRD EGFR cohort } \\
(\mathrm{n}=422)\end{array}$ \\
\hline $40 \mathrm{mg}$ & $350(82.9)$ \\
$30 \mathrm{mg}$ & $55(13.0)$ \\
$20 \mathrm{mg}$ & $3(0.7)$ \\
Unknown & $14(3.3)$ \\
ECOG PS, n (\%) & \\
$<2$ & $306(72.5)$ \\
$\geq 2$ & $52(12.3)$ \\
Unknown & $64(15.2)$
\end{tabular}

a , patients may have had metastases in more than one location; b, patients appear in one EGFR mutation category only, patients with $>1$ documented EGFR mutation were classed as having compound mutations; ${ }^{c}$, patients may appear in more than one EGFR mutation category. KATRD, Korean Academy of Tuberculosis and Respiratory Disease; EGFR, epidermal growth factor receptor; NSCLC, non-small cell lung cancer; MRI, magnetic resonance imaging; CT, computerized tomography; $A L K$, anaplastic lymphoma kinase; ECOG PS, Eastern Cooperative Oncology Group performance status.

had a CR and 223 had a PR, for an overall response rate (ORR) of 62.6\% (Table 2). A further 107 (29.2\%) patients had SD; therefore, the disease control rate (DCR) was $91.8 \%$.

Overall, patients with tumors harboring mutations in exon 20 (alone or as a compound mutation) had a lower ORR [26.7\% (1 CR and 3 PRs among 15 patients)] compared with those with tumors harboring mutations in exons 18 , 19, and 21 only (Figure 1). Afatinib showed strong activity against compound mutations, including an ORR of $100 \%$ in four patients with tumors harboring mutations in both exon 18 and 21 (Figure 1). Patients with de novo T790M mutations (either alone or in combination with another common/uncommon EGFR mutation) had the lowest ORR (25.0\%, Table S1). Patients with the major uncommon mutation S768I (n=7) had an ORR of $42.9 \%$. Two patients had exon 20 insertions: one of these patients with a V769_D770insASV mutation achieved PR, and another with an Ins.3dup mutation achieved SD.

Of the 168 patients with baseline brain metastases, $122(72.6 \%)$ patients no longer had brain metastases after afatinib treatment, $28(16.7 \%)$ patients still had brain metastases and presence of brain metastases was unknown for the remaining 18 (10.7\%) patients. Among the 249 


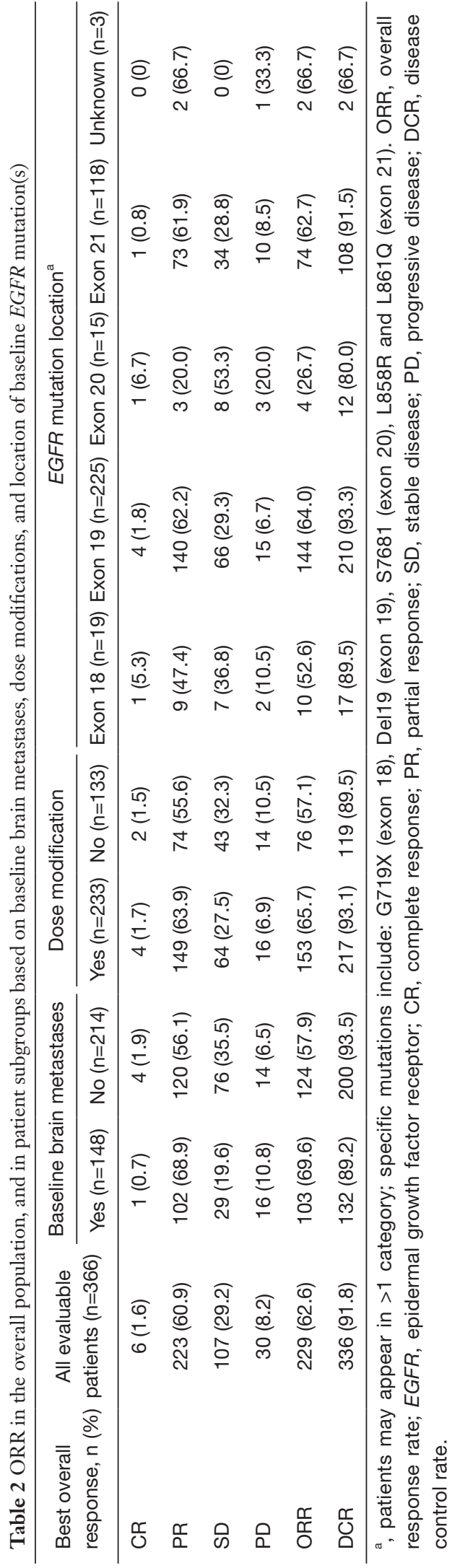

patients without brain metastases at baseline, 44 (17.7\%) patients developed brain metastases after starting afatinib treatment, $185(74.3 \%)$ patients remained free from brain metastases, and the remaining $20(8.0 \%)$ patients had unknown status after afatinib treatment.

Dose reduction did not appear to impact efficacy; ORR in patients with a dose reduction was $65.7 \%$, compared with $57.1 \%$ in those who did not have a dose reduction (Table 2). Among patients with at least one dose reduction, ORR was highest $(69.2 \%)$ in those who received a final afatinib dose of $30 \mathrm{mg} /$ day.

\section{$T T D$}

Among 419 patients with available data, median TTD was 17.8 months [95\% confidence interval (CI): 15.6-20.5; Figure 2A; Table 3], and the 3- and 5-year TTD rates were $28.7 \%$ and $15.9 \%$, respectively.

Patients with a Del19 mutation had significantly longer median TTD than those without Del19 mutations (20.5 vs. 15.4 months; $\mathrm{P}=0.0086$; Table 3). Conversely, median TTD was shorter in patients with tumors harboring an L858R mutation than those without L858R mutations (15.4 vs. 19.6 months; $\mathrm{P}=0.0166)$. Patients with a de novo T790M mutation also had significantly shorter TTD than those without T790M at baseline (median 8.1 vs. 18.2 months; $\mathrm{P}=0.0174)$.

Median TTD was significantly longer in patients without brain metastases versus those with brain metastases at baseline (22.9 vs. 14.8 months; $\mathrm{P}=0.001$ ), and in patients with versus those without dose reductions (22.2 vs. 14.2 months; $\mathrm{P}=0.0004 ;$ Table 3). Among the 60 patients with baseline brain metastases who received afatinib as their only first-line treatment (i.e., received no brain surgery or radiotherapy), median TTD was 14.2 months (95\% CI: 11.2-19.0).

\section{OS}

Median OS was not reached (NR) in the treated set (95\% CI: 40.3 months-NR) after a median follow-up of 15.6 months; the 3 - and 5 -year OS rates were $67.2 \%$ and $52.9 \%$, respectively (Figure $2 B$ and Table 3). Median OS was also NR for $E G F R$ mutation type when comparing patients with tumors with Del19, L858R and T790M mutations versus those without those mutations. Additionally, median OS was NR when comparing patients with uncommon mutations (G719X, S7681, and L861Q) versus those 


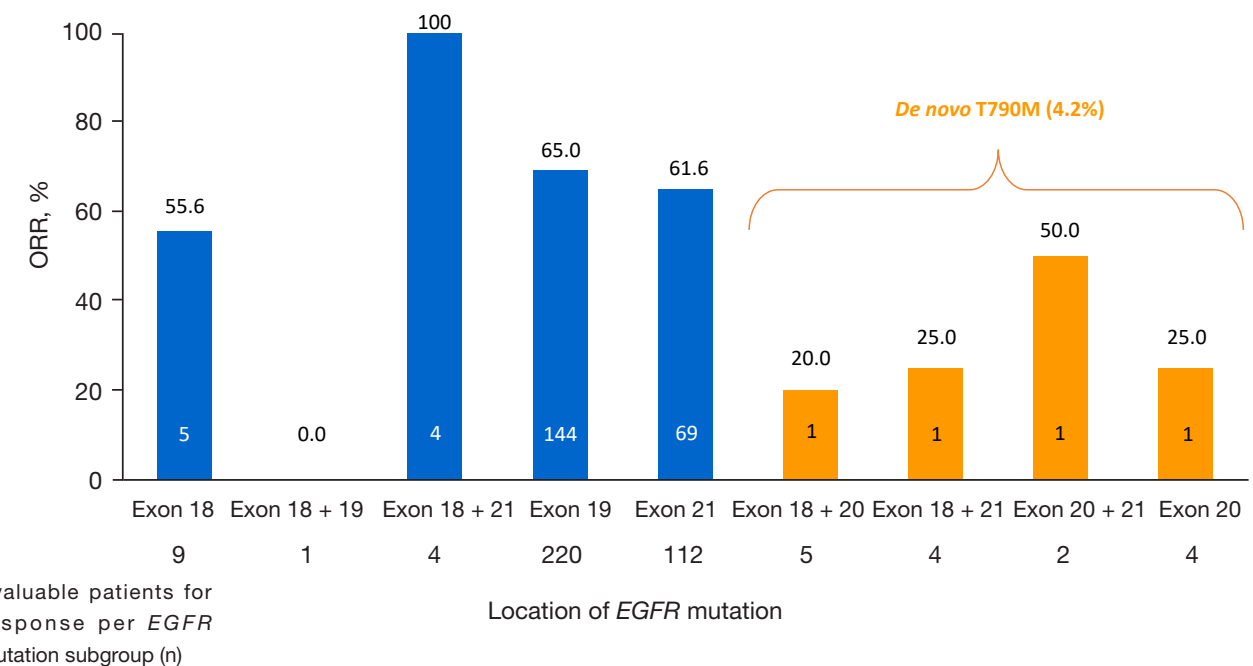

Figure 1 Response rate according to location of EGFR mutation(s) at initial biopsy, grouped by single and compound mutations (n=361). Specific mutations include: G719X (exon 18), Del19 (exon 19), S7681 (exon 20), L858R and L861Q (exon 21). EGFR, epidermal growth factor receptor; ORR, overall response rate.

without these mutations. Similar to TTD, median OS was significantly longer in patients without versus those with brain metastases at baseline (NR vs. 40.3 months; $\mathrm{P}=0.0009$ ) and in patients with versus without dose reductions (NR vs. 40.3 months; $\mathrm{P}=0.0117$; Table 3).

\section{Safety}

Two-hundred and fifty-three (60.0\%) patients had at least one TRAE, and $92(21.8 \%)$ patients had grade $\geq 3$ TRAEs (117 events). The most common TRAEs (any grade/grade $\geq 3)$ were diarrhea $(\mathrm{n}=132,31.3 \% ; \mathrm{n}=36,8.5 \%)$ and rash $(\mathrm{n}=97,23.0 \% ; \mathrm{n}=34,8.1 \%$; Table 4$)$. There were two grade 4 TRAEs (hyperkalemia and acute kidney injury) and four grade 5 TRAEs [pneumonia $(\mathrm{n}=2)$, pneumonitis $(\mathrm{n}=1)$, and respiratory failure $(\mathrm{n}=1)]$.

\section{Dose modifications and discontinuations}

Two-hundred and fifty-six $(60.7 \%)$ patients had afatinib dose modifications, predominantly due to AEs [226 patients $(88.3 \%)]$. The two most commonly reported AEs leading to dose modification were diarrhea and rash (Table 4). The remaining patients had dose modifications due to investigator's decision [ 25 patients $(9.8 \%)]$ and other reasons [five patients $(2.0 \%)$ ]. Afatinib was reduced to
$30 \mathrm{mg}$ in $156(60.9 \%)$ patients, and to $20 \mathrm{mg}$ in 94 (36.7\%) patients. Six $(2.3 \%)$ patients with dose modifications had a final dose of $40 \mathrm{mg}$ (their starting dose of $40 \mathrm{mg}$ was initially reduced and later increased). Of the 273 patients who had discontinued afatinib, $34(12.5 \%)$ discontinued due to AEs, of which 18 (6.6\%) switched treatment from afatinib to gefitinib due to toxicity.

\section{Detection of T790M mutation at re-biopsy}

In total, 57 patients had EGFR mutation data available from a second biopsy performed following progression on afatinib. The most common method for detection of EGFR mutations was PNA-clamp ( $\mathrm{n}=50)$. As with initial biopsies, second biopsies were performed most commonly using tissue samples $(\mathrm{n}=50)$; other sample types included pleural effusions ( $\mathrm{n}=3)$ and cerebrospinal fluid $(\mathrm{n}=2)$.

Of 57 patients with EGFR mutation status available at both initial biopsy and rebiopsy, the T790M mutation was detected in 18 (31.6\%) patients at the second biopsy (Table S2). Two patients with T790M at initial biopsy no longer had T790M at rebiopsy. At the second biopsy, T790M was detected in $14 / 35$ (40.0\%) patients who had tumors harboring only Del19 initially, compared with 2/10 (20.0\%) patients with tumors harboring only L858R initially and 1/6 (16.7\%) patients with L858R compound 

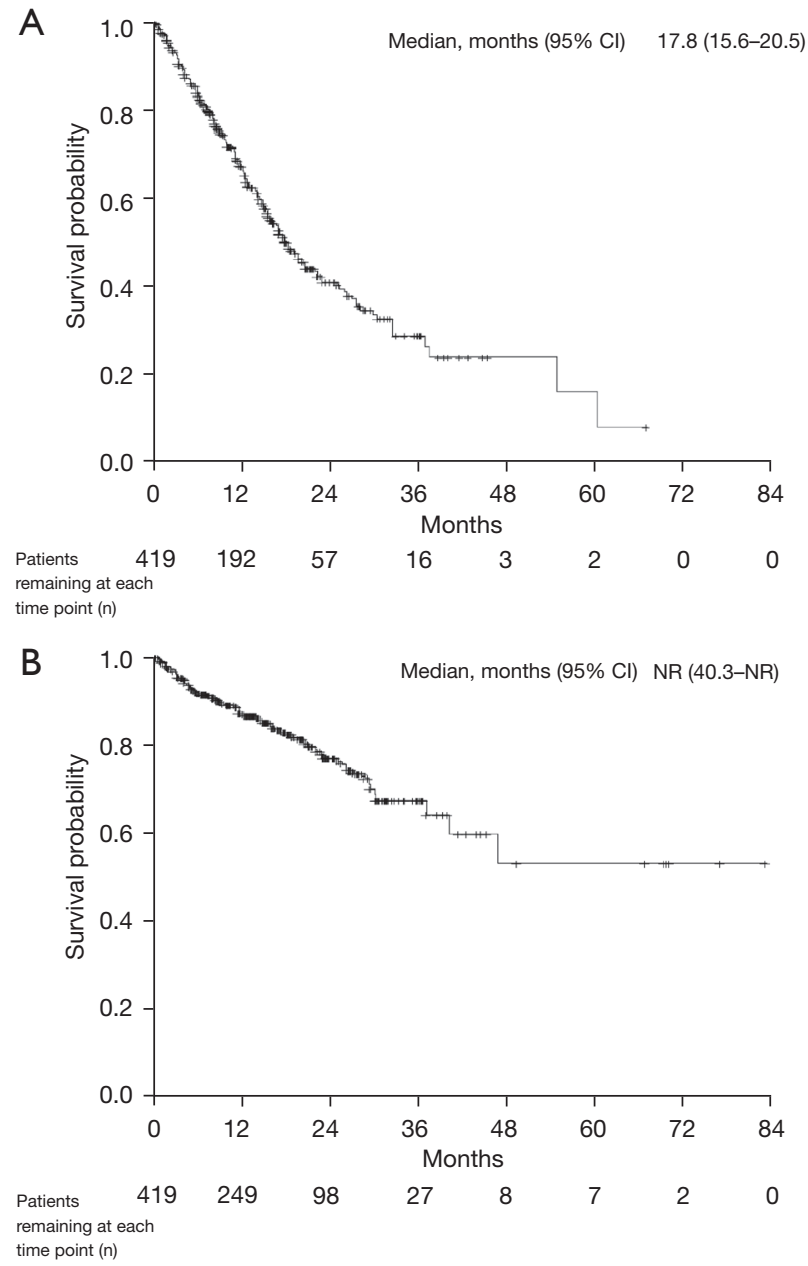

Figure 2 Kaplan-Meier curves of TTD (A) and OS (B) (n=419). $\mathrm{CI}$, confidence interval; NR, not reached; TTD, time-to-treatment discontinuation; OS, overall survival.

mutations at initial biopsy.

\section{Subsequent treatment and outcomes}

In total, 138 patients received second-line therapy after progression on afatinib (Table S3). The most common subsequent treatment was pemetrexed [65 patients $(47.1 \%)$, followed by osimertinib [21 patients $(15.2 \%)]$ and gemcitabine [16 patients (11.6\%)].

Median OS was 30.5 months (95\% CI: 27.5-NR) in patients who received afatinib followed by cytotoxic chemotherapy $(n=90)$; the 3 -year survival rate was $49.1 \%$. For patients who received sequential afatinib and osimertinib, median OS was 37.7 months (95\% CI: 23.447.6), median TTD was 32.0 months (95\% CI: 14.6-49.4),

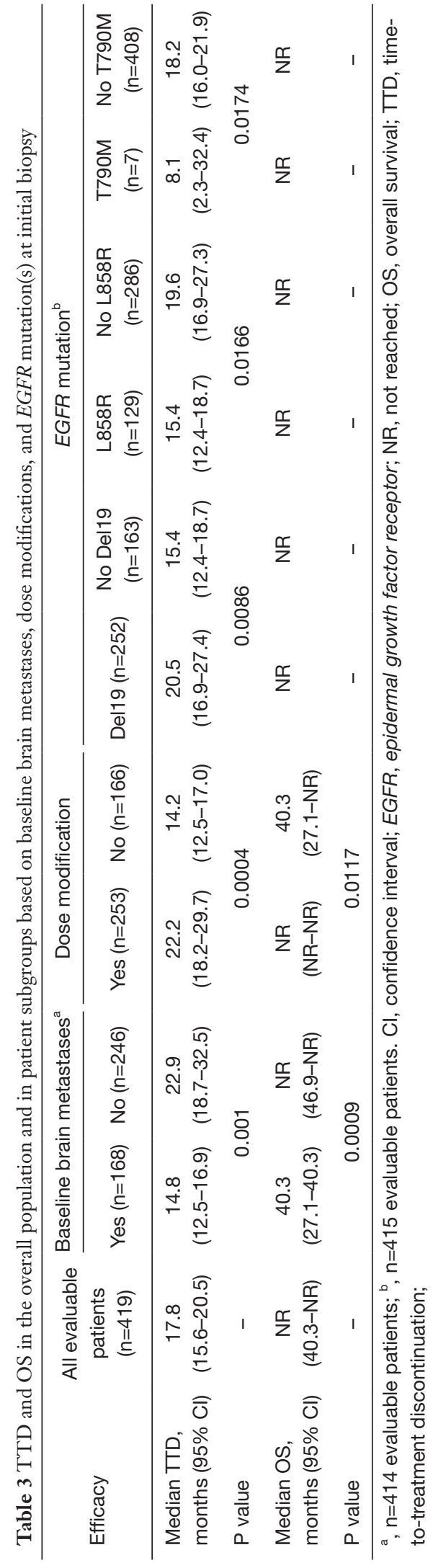


Table 4 Most common TRAEs (occurring in $\geq 3$ patients overall) and AEs leading to dose modification in the overall population ( $\mathrm{n}=422$ )

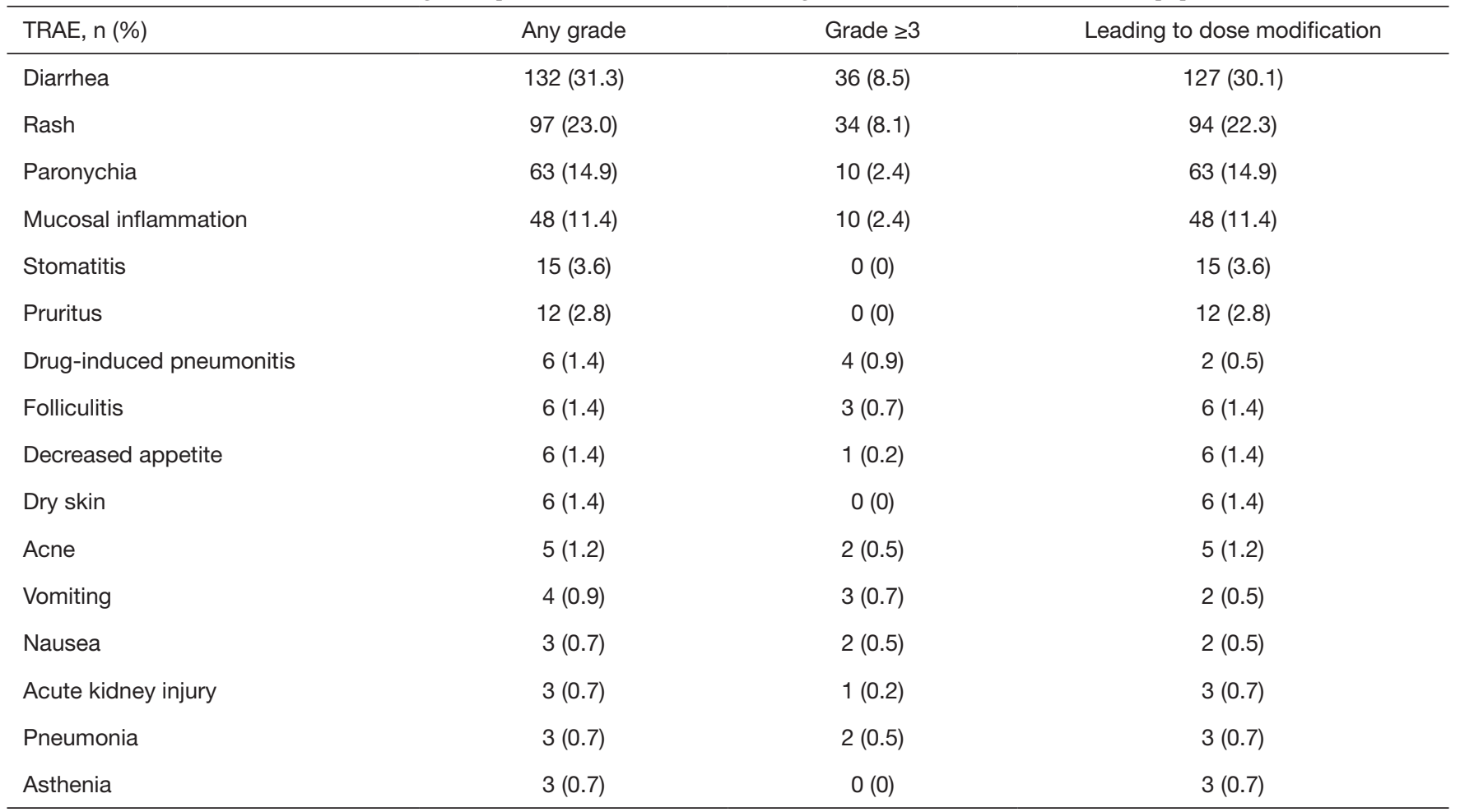

TRAE, treatment-related adverse event; AEs, adverse events.

and the 3 -year survival was rate was $72.7 \%$.

\section{Discussion}

Real-world studies are increasingly recognized by regulatory bodies as being important for monitoring the safety and effectiveness of approved agents in routine clinical practice and to guide approval decisions of new treatments (16). In this regard, the results of the current study provide valuable insight into the clinical characteristics and treatment outcomes in patients with $E G F R \mathrm{~m}^{+}$NSCLC treated with first-line afatinib, adding to previous real-world experience of afatinib use in Korean patients $(18,19)$.

In this analysis of the KATRD EGFR cohort, patient and clinical characteristics were comparable to those previously reported in patients receiving afatinib in a real-world setting in South Korea $(18,19)$. Patient subgroups included those that are generally excluded from randomized clinical trials, such as those with brain metastases or with tumors harboring uncommon EGFR mutations.

Afatinib showed encouraging efficacy in this broad patient population. Response rates were in line with those observed with first-line afatinib in the pivotal LUX-
Lung trials (63\% in the KATRD cohort vs. $69 \%$ in LUXLung 3, 67\% in LUX-Lung 6, and 70\% in LUX-Lung 7) (9-11). Moreover, although not directly comparable due to differences in the study designs, patient populations, and statistical methods, median TTD (17.8 months) compared favorably with the median PFS values of 11.1, 11.0, and 11.0 months observed in LUX-Lung 3, 6, and 7, respectively $(9,10,20)$, and was similar to median PFS times, of 19.1 and 17.0 months, observed in previous real-world studies in Korean patients with EGFRm ${ }^{+} \operatorname{NSCLC~}(18,19)$. OS data were also particularly impressive in the KATRD EGFR cohort; median OS was NR after a median follow-up of 15.6 months, and 3- and 5-year OS rates were $67.2 \%$ and $52.9 \%$.

In addition to tumors harboring mutations in exons 19 and 21 (including Del19 and L858R mutations), afatinib demonstrated clinical activity against mutations in exon 18 , which is consistent with preclinical and clinical evidence that such mutations are sensitive to secondgeneration EGFR TKIs $(12,21)$. This finding is also notable as exon 18 mutations are often present in compound mutations (22). Indeed, afatinib showed evidence of activity against compound mutations, including an ORR of $100 \%$ 
in patients with tumors harboring mutations in both exon 18 and exon 21, although there were only a small number of patients in this subgroup $(n=4)$.

Compared with other EGFR mutation types, patients with tumors harboring mutations in exon 20 had a lower ORR (26.7\%). This group included patients with de novo T790M mutations (with an ORR of $25 \%$ ), for whom a shorter TTD was also observed. This is in line with previous findings across the LUX-Lung 2, 3 and 6 trials that clinical benefit with afatinib was lower in patients with T790M mutations (14). Afatinib showed activity against the major uncommon mutation S768I, consistent with previous data (14). Afatinib also showed activity in two patients with tumors harboring exon 20 insertions. Although a post hoc analysis of the LUX-Lung 2, 3, and 6 trials suggested only very limited activity of afatinib against exon 20 insertions (14), the more sensitive variants may not have been highly represented in these trials. EGFR exon 20 mutations are structurally and functionally heterogeneous, with such differences having implications for their responses to EGFR TKIs and, accordingly, exon 20 mutations should not be considered as a single entity. For example, insertions proximal to codon 769 are predicted to retain sensitivity to EGFR TKIs based on in silico modeling (23). Furthermore, preclinical data $(12,24)$, together with accumulating realworld evidence (25-27), suggest that afatinib could be clinically active against some specific types of $E G F R$ exon 20 insertions.

Additional findings support the use of afatinib as a treatment option for advanced NSCLC in patients with uncommon $E G F R$ mutations. In this patient population, afatinib is potentially more effective versus first-generation TKIs (28). In EGFR TKI-naive NSCLC patients $(\mathrm{n}=315)$ with uncommon $E G F R$ mutations, treatment with afatinib was associated with a median time to treatment failure (TTF) of 10.8 months (95\% CI: 8.1-16.6) and an ORR of $60.0 \%$ among those with 'major' uncommon mutations (G719X, L861Q and S7681, with or without any other mutation except T790M or an exon 20 insertion) (29). For patients with compound mutations in this database analysis, median TTF was 14.7 months (95\% CI: 6.8-18.5) and ORR was $77.1 \%$ (29). In a recent prospective noninterventional study in NSCLC patients with EGFR mutations who received first-line afatinib, median PFS was 10.7 months and ORR was $83.3 \%$ in those with uncommon EGFR mutations; similar results were reported in those with brain metastases (30).

The finding that TTD was significantly longer for patients with Del19-positive versus Del19-negative tumors but not for those with L858R-positive versus L858Rnegative tumors corroborates previous reports that patients with NSCLC harboring Del19 mutations have consistently shown better outcomes with EGFR TKIs than those with L858R-positive tumors (31-33). Although it has been proposed that this may reflect higher rates of de novo T790M mutations in L858R-positive tumors (34), we observed a similar prevalence of T790M in patients with Del19- and L858R-positive tumors at initial (pretreatment) biopsy.

Patients with brain metastases showed a decrease in both TTD and OS compared with those without brain metastases, as expected for this group with a generally poor prognosis (15). Nevertheless, at 14.8 and 40.3 months, respectively, TTD and OS were encouraging in patients with brain metastases. Similar results were also observed in 60 patients with baseline brain metastases who received first-line afatinib as their only treatment (median TTD 14.2 months; median OS 40.3 months). Of note, in the LUX-Lung 3, 6 and 7 studies, median PFS with afatinib was numerically shorter in patients with versus without baseline brain metastases, although the magnitude of PFS improvement compared with chemotherapy or gefitinib was similar regardless of the presence of baseline brain metastases $(11,35)$.

One limitation of this study is that intracranial responses to afatinib were not formally evaluated; therefore, it is not possible to draw any definitive conclusions of the effectiveness of afatinib on existing brain metastases. Nonetheless, our finding that 122 patients with baseline brain metastases no longer had brain metastases after afatinib treatment suggests an intracranial response to afatinib and provides evidence of CNS activity. This is consistent with preclinical evidence that afatinib crosses the blood-brain barrier at concentrations sufficient to be pharmacologically active, as well as previous clinical evidence of the activity of afatinib against existing brain metastases (15). Afatinib may also offer protection against CNS progression. In a competing risk analysis of LUXLung 3 and 6, de novo CNS progression was observed in only $5 \%$ of patients after 24 months, compared with a non-CNS progression rate of $71 \%$ (15). Overall, these data suggest that, despite the generally poorer prognosis of patients with brain metastases, afatinib shows clinical activity in this patient population.

Afatinib demonstrated a manageable safety profile, consistent with that observed in clinical trials (9-11) and 
in the real-world setting (36). The most common TRAEs were diarrhea and rash, and no new safety signals were identified. Data from clinical trials and the real-world setting demonstrate that afatinib-related AEs, including diarrhea and rash, can be managed effectively with tolerability-guided dose adjustment, and, in the majority of cases, dose-reduction and/or supportive care treatments enable patients to continue treatment for as long as they derive clinical benefit (36-38). In the current study, $61 \%$ of patients received dose modifications, mainly due to AEs; this is higher than the rate of afatinib dose reductions in LUX-Lung 3, 6 and 7 (9-11), but is in line with the rate observed among patients who started on $40 \mathrm{mg}$ afatinib in the real-world study, RealGiDo (36). These differences may be attributed to increasing awareness among physicians regarding the importance of tolerability-guided dose adjustment in managing afatinib-related AEs, but may also reflect the overall poorer health of patients treated in the real-world practice compared with those enrolled in clinical trials. Consistent with previous results from clinical trials and real-world data (36-38), our analysis showed that efficacy was not adversely impacted by afatinib dose adjustment. In our analysis, TTD and OS were significantly improved in patients with versus those without afatinib dose modifications (Table 3), although it may be that patients who required dose adjustments were receiving afatinib for a longer period of time than those not requiring afatinib dose modifications.

Unfortunately, acquired resistance to EGFR TKIs is almost inevitable, regardless of which TKI is given in first line (39). For first- and second-generation EGFR TKIs, resistance arises predominantly due to the 'gatekeeper' T790M mutation, identified in approximately $50-70 \%$ of tumors upon progression (40-42), albeit possibly affecting a slightly lower proportion of afatinib-treated patients than those treated with first-generation TKIs (43). In the current study, among the 57 patients with available data on EGFR mutation status at both initial and rebiopsy, T790M was detected in $31.6 \%(\mathrm{n}=18)$ of patients at second biopsy. This is lower than the rates reported in several previous studies, although detection rates can vary greatly depending on the type of samples and mutation test used, with the highest rates having been observed with sensitive plasma-based assays (40). Of note, most of the re-biopsies (50/57) for patients in the KATRD cohort employed tissuebased samples, which, despite being considered the gold standard for detection of T790M, can be confounded by heterogeneous presence of T790M in the tumor tissue, meaning that mutations may be missed if tissue biopsy is taken from a single tumor region. Regardless of overall frequency, our finding that T790M was detected more often in patients with Del19-positive tumors than in those with L858R-positive disease is in agreement with reports that patients with NSCLC harboring Del19 mutations have a higher likelihood of acquiring T790M (44).

Subsequent treatment choice depends on a number of criteria. Identification of particular molecular aberrations can guide these decisions, highlighting the importance of testing upon progression. For patients who develop T790M resistance mutations following first-line afatinib, osimertinib, which has shown striking activity in patients with T790M-positive NSCLC after failure of firstline TKIs (45), would represent the optimal subsequent treatment option. Findings of a real-world observational study in NSCLC patients with EGFR mutations in Italy indicated that the vast majority of patients (114 of 120; 95.0\%) who developed T790M mutations after first-line EGFR TKI treatment (erlotinib, gefitinib or afatinib) received targeted therapy with osimertinib (46). In the current study, the majority of patients went on to receive chemotherapy such as pemetrexed or gemcitabine, while only $15.2 \%$ received subsequent osimertinib. Although this may partly reflect the relatively low rate of T790M mutations detected in this study, it must also be considered that osimertinib was not approved in second-line EGFRm ${ }^{+}$ NSCLC in South Korea until May 2016, and patients in the KATRD cohort started on first-line afatinib between April 2007 and December 2018. Therefore, the availability of osimertinib will have been limited at the time that many of these patients went on to receive second-line treatment. Of note, in our study, median OS was longer for patients who received osimertinib after discontinuing afatinib than for those who received second-line chemotherapy (37.7 vs. 30.5 months). These results are consistent with data from the observational GioTag study which assessed real-world outcomes among patients with T790M NSCLC who received sequential afatinib and osimertinib (median OS 37.6 months) (47).

Osimertinib is now also established as a first-line treatment option for EGFRm ${ }^{+}$(Del19 or L858R) NSCLC, having demonstrated a significant PFS and OS benefit versus a first-generation EGFR TKI (erlotinib/gefitinib) in the phase III FLAURA trial (48). However, osimertinib did not definitively confirm OS benefit in the Asian subgroup. In addition, mechanisms of resistance to osimertinib are more heterogeneous than for first- and second-generation 
TKIs, meaning that there are no clear targeted treatment options following first-line osimertinib, and most patients will receive chemotherapy in second line. There is an argument, therefore, that rather than using osimertinib up front, sequential treatment with afatinib followed by osimertinib may be a better treatment strategy in order to maximize TTD with EGFR TKIs and delay the need for chemotherapy. The use of combination regimens, such as erlotinib plus either ramucirumab or bevacizumab, has also provided encouraging PFS results as a first-line treatment option $(49,50)$. Also of interest are findings from a retrospective cohort study in Japan, which showed a statistically significant survival advantage for firstline treatment with afatinib versus osimertinib among a subgroup of NSCLC patients without brain metastases who had EGFR L858R mutations (51).

Our study has several limitations in addition to the retrospective study design and the aforementioned lack of formal evaluation of intracranial responses to afatinib. Although the study was conducted over a period of $>11$ years, the median follow-up period of 15.6 months was relatively short in comparison. Moreover, the data cutoff was in early April 2019 with the last patient included in December 2018, resulting in a minimal follow-up period of only a few months. The Kaplan-Meier curves of TTD and OS (Figure 2) also show that many patients were censored in the first 24 months. Additionally, the study was limited by the high number of patients for whom the method of EGFR mutation detection at initial biopsy was not recorded (66 of 422 patients; $15.6 \%$ ) and by the high proportion of patients who discontinued afatinib and were lost to followup (30 of 273 patients; 11.0\%). Arguably, the latter group of patients could have been excluded from the retrospective analysis. The rate of re-biopsy and resistance testing following progression on afatinib in this study was low (T790M mutation detected in 18 of 57 patients at re-biopsy; $31.6 \%$ ), as was the use of osimertinib as second-line therapy after progression on afatinib (21 of 138 patients; $15.2 \%$ ). In contrast, a more recent retrospective analysis conducted in Korea identified a much higher number of patients $(n=126)$ who received osimertinib as a second-line treatment and presented T790M mutation after afatinib (52).

\section{Conclusions}

Overall, the KATRD EGFR cohort provides extensive details of diagnosis, treatment and outcomes in Korean patients with $E G F R \mathrm{~m}^{+}$receiving first-line afatinib in a realworld setting. While the results should be considered in the context of the retrospective nature of the trial, afatinib was shown to provide clinical benefit, and was well tolerated, with no new safety signals. Efficacy was encouraging in the overall cohort and across patient subgroups, including those with baseline brain metastases and those with uncommon EGFR mutations. Management of AEs with afatinib dose reductions facilitated a long TTD, thus prolonging the chemotherapy-free period for many patients.

\section{Acknowledgments}

Medical writing support for the development of this manuscript, under the direction of the authors, was provided by Fiona Scott, contracted on behalf of Ashfield MedComms, an Ashfield Health company, and funded by Boehringer Ingelheim Inc. (BI). BI was given the opportunity to review the manuscript for medical and scientific accuracy as well as intellectual property considerations.

Funding: The authors received no direct compensation related to the development of the manuscript. BI was involved in the reviewing of this paper for medical and scientific accuracy as it relates to BI substances, as well as intellectual property considerations; however, BI had no role in the study design, collection, analysis, or interpretation of the results of this study.

\section{Footnote}

Reporting Checklist: The authors have completed the STROBE reporting checklist. Available at https://dx.doi. org/10.21037/tlcr-21-501

Data Sharing Statement: Available at https://dx.doi. org/10.21037/tlcr-21-501

Conflicts of Interest: All authors have completed the ICMJE uniform disclosure form (available at https:// dx.doi.org/10.21037/tlcr-21-501). YCK reports receiving research grant and honorarium from AstraZeneca, research grant from Boehringer Ingelheim, and honorarium from Roche outside the submitted work. TWJ reports receiving honoraria and grants or funds from BI outside the submitted work. The other authors have no conflicts of interest to declare. 
Ethical Statement: The authors are accountable for all aspects of the work in ensuring that questions related to the accuracy or integrity of any part of the work are appropriately investigated and resolved. The study was conducted in accordance with the guidelines of the Helsinki Declaration (as revised in 2013). The study was approved by the institutional ethics review boards of: Korea University Guro Hospital (2018GR0013), Asan Medical Center (2018-0012), Yonsei University Gangnam Severance Hospital (3-2020-0003), Konkuk University Medical Center (KUH1010909), Catholic University Seoul St. Mary's Hospital (KC20RCDI0129), Wonkwang University Hospital (WKUH-201606-HR-058), Inha University Hospital Institutional Review Board (202001-016), Chungnam National University Institutional Review Board (CNUH 2020-02-022-006), Kyungpook National University Chilgok Hospital Institutional Review Board (KNUCH 2020-01-010), Hallym University Sacred Heart Hospital Institutional Review Board (HALLYM 2020-07-041), Chonnam National University Hwasun Hospital Institutional Review Board (CNUHH-2017-179), Daegu Catholic University Medical Center Institutional Review Board (CR-18-097), Institutional Review Board of Severance Hospital (4-2019-1214), Pusan National University Yangsan Hospital Institutional Review Board (05-2020-006), and Kosin University Gospel Hospital Institutional Review Board (KUGH 2017-11-030). Individual consent for this retrospective analysis was waived.

Open Access Statement: This is an Open Access article distributed in accordance with the Creative Commons Attribution-NonCommercial-NoDerivs 4.0 International License (CC BY-NC-ND 4.0), which permits the noncommercial replication and distribution of the article with the strict proviso that no changes or edits are made and the original work is properly cited (including links to both the formal publication through the relevant DOI and the license). See: https://creativecommons.org/licenses/by-nc-nd/4.0/.

\section{References}

1. American Cancer Society. Key statistics for lung cancer 2020. Available online: https://www.cancer.org/cancer/ lung-cancer/about/key-statistics.html

2. Jung KW, Won YJ, Hong S, et al. Prediction of Cancer Incidence and Mortality in Korea, 2020. Cancer Res Treat 2020;52:351-8.

3. Chan BA, Hughes BG. Targeted therapy for non-small cell lung cancer: current standards and the promise of the future. Transl Lung Cancer Res 2015;4:36-54.

4. Choi CM, Kim HC, Jung CY, et al. Report of the Korean Association of Lung Cancer Registry (KALC-R), 2014. Cancer Res Treat 2019;51:1400-10.

5. Torti D, Trusolino L. Oncogene addiction as a foundational rationale for targeted anti-cancer therapy: promises and perils. EMBO Mol Med 2011;3:623-36.

6. Girard N. Optimizing outcomes in EGFR mutationpositive NSCLC: which tyrosine kinase inhibitor and when? Future Oncol 2018;14:1117-32.

7. Solca F, Dahl G, Zoephel A, et al. Target binding properties and cellular activity of afatinib (BIBW 2992), an irreversible ErbB family blocker. J Pharmacol Exp Ther 2012;343:342-50.

8. Li D, Ambrogio L, Shimamura T, et al. BIBW2992, an irreversible EGFR/HER2 inhibitor highly effective in preclinical lung cancer models. Oncogene 2008;27:4702-11.

9. Sequist LV, Yang JC, Yamamoto N, et al. Phase III study of afatinib or cisplatin plus pemetrexed in patients with metastatic lung adenocarcinoma with EGFR mutations. J Clin Oncol 2013;31:3327-34.

10. Wu YL, Zhou C, Hu CP, et al. Afatinib versus cisplatin plus gemcitabine for first-line treatment of Asian patients with advanced non-small-cell lung cancer harbouring EGFR mutations (LUX-Lung 6): an open-label, randomised phase 3 trial. Lancet Oncol 2014;15:213-22.

11. Park K, Tan EH, O'Byrne K, et al. Afatinib versus gefitinib as first-line treatment of patients with EGFR mutationpositive non-small-cell lung cancer (LUX-Lung 7): a phase 2B, open-label, randomised controlled trial. Lancet Oncol 2016;17:577-89.

12. Kohsaka S, Nagano M, Ueno T, et al. A method of highthroughput functional evaluation of EGFR gene variants of unknown significance in cancer. Sci Transl Med 2017;9:eaan6566.

13. Masood A, Kancha RK, Subramanian J. Epidermal growth factor receptor (EGFR) tyrosine kinase inhibitors in non-small cell lung cancer harboring uncommon EGFR mutations: Focus on afatinib. Semin Oncol 2019;46:271-83.

14. Yang JC, Sequist LV, Geater SL, et al. Clinical activity of afatinib in patients with advanced non-small-cell lung cancer harbouring uncommon EGFR mutations: a combined post-hoc analysis of LUX-Lung 2, LUX-Lung 3, and LUX-Lung 6. Lancet Oncol 2015;16:830-8.

15. Hochmair M. Medical Treatment Options for Patients 
with Epidermal Growth Factor Receptor MutationPositive Non-Small Cell Lung Cancer Suffering from Brain Metastases and/or Leptomeningeal Disease. Target Oncol 2018;13:269-85. Erratum in: Target Oncol 2018;13:667.

16. Khozin S, Blumenthal GM, Pazdur R. Real-world Data for Clinical Evidence Generation in Oncology. J Natl Cancer Inst 2017.

17. Park K, Wan-Teck Lim D, Okamoto I, et al. First-line afatinib for the treatment of EGFR mutation-positive nonsmall-cell lung cancer in the 'real-world' clinical setting. Ther Adv Med Oncol 2019;11:1758835919836374.

18. Kim Y, Lee SH, Ahn JS, et al. Efficacy and Safety of Afatinib for EGFR-mutant Non-small Cell Lung Cancer, Compared with Gefitinib or Erlotinib. Cancer Res Treat 2019;51:502-9.

19. Park K, Kim JS, Kim JH, et al. An open-label expanded access program of afatinib in EGFR tyrosine kinase inhibitor-naïve patients with locally advanced or metastatic non-small cell lung cancer harboring EGFR mutations. BMC Cancer 2021;21:802.

20. Paz-Ares L, Tan EH, O'Byrne K, et al. Afatinib versus gefitinib in patients with EGFR mutation-positive advanced non-small-cell lung cancer: overall survival data from the phase IIb LUX-Lung 7 trial. Ann Oncol 2017;28:270-7.

21. Kobayashi Y, Togashi Y, Yatabe Y, et al. EGFR Exon 18 Mutations in Lung Cancer: Molecular Predictors of Augmented Sensitivity to Afatinib or Neratinib as Compared with First- or Third-Generation TKIs. Clin Cancer Res 2015;21:5305-13.

22. O'Kane GM, Bradbury PA, Feld R, et al. Uncommon EGFR mutations in advanced non-small cell lung cancer. Lung Cancer 2017;109:137-44.

23. Arcila ME, Nafa K, Chaft JE, et al. EGFR exon 20 insertion mutations in lung adenocarcinomas: prevalence, molecular heterogeneity, and clinicopathologic characteristics. Mol Cancer Ther 2013;12:220-9.

24. Hirano T, Yasuda H, Tani T, et al. In vitro modeling to determine mutation specificity of EGFR tyrosine kinase inhibitors against clinically relevant EGFR mutants in non-small-cell lung cancer. Oncotarget 2015;6:38789-803.

25. Cai Y, Wang X, Guo Y, et al. Successful treatment of a lung adenocarcinoma patient with a novel EGFR exon 20-ins mutation with afatinib: A case report. Medicine (Baltimore) 2019;98:e13890.

26. Costa M, Lewgoy J. P3.13-13 Afatinib in Lung Adenocarcinoma Harboring de novo EGFR Exon 20
Insertions. J Thoracic Oncol 2018;13:S981.

27. Chan RT. Afatinib for an EGFR exon 20 insertion mutation: A case report of progressive stage IV metastatic lung adenocarcinoma with 54 months' survival. Asia Pac J Clin Oncol 2018;14 Suppl 1:7-9.

28. Tanaka I, Morise M, Kodama Y, et al. Potential for afatinib as an optimal treatment for advanced non-small cell lung carcinoma in patients with uncommon EGFR mutations. Lung Cancer 2019;127:169-71.

29. Yang JC, Schuler M, Popat S, et al. Afatinib for the Treatment of NSCLC Harboring Uncommon EGFR Mutations: A Database of 693 Cases. J Thorac Oncol 2020;15:803-15.

30. Brückl WM, Reck M, Griesinger F, et al. Afatinib as firstline treatment in patients with EGFR-mutated non-small cell lung cancer in routine clinical practice. Ther Adv Med Oncol 2021;13:17588359211012361.

31. Jackman DM, Yeap BY, Sequist LV, et al. Exon 19 deletion mutations of epidermal growth factor receptor are associated with prolonged survival in non-small cell lung cancer patients treated with gefitinib or erlotinib. Clin Cancer Res 2006;12:3908-14.

32. Riely GJ, Pao W, Pham D, et al. Clinical course of patients with non-small cell lung cancer and epidermal growth factor receptor exon 19 and exon 21 mutations treated with gefitinib or erlotinib. Clin Cancer Res 2006;12:839-44.

33. Yang JC, Wu YL, Schuler M, et al. Afatinib versus cisplatin-based chemotherapy for EGFR mutation-positive lung adenocarcinoma (LUX-Lung 3 and LUX-Lung 6): analysis of overall survival data from two randomised, phase 3 trials. Lancet Oncol 2015;16:141-51.

34. Yu HA, Arcila ME, Hellmann MD, et al. Poor response to erlotinib in patients with tumors containing baseline EGFR T790M mutations found by routine clinical molecular testing. Ann Oncol 2014;25:423-8.

35. Schuler M, Wu YL, Hirsh V, et al. First-Line Afatinib versus Chemotherapy in Patients with Non-Small Cell Lung Cancer and Common Epidermal Growth Factor Receptor Gene Mutations and Brain Metastases. J Thorac Oncol 2016;11:380-90.

36. Halmos B, Tan EH, Soo RA, et al. Impact of afatinib dose modification on safety and effectiveness in patients with EGFR mutation-positive advanced NSCLC: Results from a global real-world study (RealGiDo). Lung Cancer 2019;127:103-11.

37. Yang JC, Sequist LV, Zhou C, et al. Effect of dose adjustment on the safety and efficacy of afatinib for EGFR 
mutation-positive lung adenocarcinoma: post hoc analyses of the randomized LUX-Lung 3 and 6 trials. Ann Oncol 2016;27:2103-10.

38. Schuler M, Tan EH, O'Byrne K, et al. First-line afatinib vs gefitinib for patients with EGFR mutationpositive NSCLC (LUX-Lung 7): impact of afatinib dose adjustment and analysis of mode of initial progression for patients who continued treatment beyond progression. J Cancer Res Clin Oncol 2019;145:1569-79.

39. Chang YS, Choi CM, Lee JC. Mechanisms of Epidermal Growth Factor Receptor Tyrosine Kinase Inhibitor Resistance and Strategies to Overcome Resistance in Lung Adenocarcinoma. Tuberc Respir Dis (Seoul) 2016;79:248-56.

40. Hochmair MJ, Buder A, Schwab S, et al. Liquid-BiopsyBased Identification of EGFR T790M MutationMediated Resistance to Afatinib Treatment in Patients with Advanced EGFR Mutation-Positive NSCLC, and Subsequent Response to Osimertinib. Target Oncol 2019;14:75-83.

41. Arcila ME, Oxnard GR, Nafa K, et al. Rebiopsy of lung cancer patients with acquired resistance to EGFR inhibitors and enhanced detection of the T790M mutation using a locked nucleic acid-based assay. Clin Cancer Res 2011;17:1169-80.

42. Yang JC, Ahn MJ, Kim DW, et al. Osimertinib in Pretreated T790M-Positive Advanced Non-SmallCell Lung Cancer: AURA Study Phase II Extension Component. J Clin Oncol 2017;35:1288-96.

43. Lee K, Kim Y, Jung HA, et al. Repeat biopsy procedures and T790M rates after afatinib, gefitinib, or erlotinib therapy in patients with lung cancer. Lung Cancer 2019;130:87-92.

44. Hochmair MJ, Morabito A, Hao D, et al. Sequential treatment with afatinib and osimertinib in patients with EGFR mutation-positive non-small-cell lung cancer: an

Cite this article as: Lee SY, Choi CM, Chang YS, Lee KY, Kim SJ, Yang SH, Ryu JS, Lee JE, Lee SY, Park JY, Kim YC, Oh IJ, Jung CY, Lee SH, Yoon SH, Choi J, Jang TW. Realworld experience of afatinib as first-line therapy for advanced EGFR mutation-positive non-small cell lung cancer in Korea. Transl Lung Cancer Res 2021;10(12):4353-4367. doi: 10.21037/ tlcr-21-501 observational study. Future Oncol 2018;14:2861-74.

45. Mok TS, Wu Y-L, Ahn M-J, et al. Osimertinib or Platinum-Pemetrexed in EGFR T790M-Positive Lung Cancer. N Engl J Med 2017;376:629-40.

46. Reale ML, Chiari R, Tiseo M, et al. Be-TeaM: An Italian real-world observational study on second-line therapy for EGFR-mutated NSCLC patients. Lung Cancer 2020;140:71-9.

47. Hochmair MJ, Morabito A, Hao D, et al. Sequential afatinib and osimertinib in patients with EGFR mutationpositive non-small-cell lung cancer: final analysis of the GioTag study. Future Oncol 2020;16:2799-808.

48. Soria JC, Ohe Y, Vansteenkiste J, et al. Osimertinib in Untreated EGFR-Mutated Advanced Non-Small-Cell Lung Cancer. N Engl J Med 2018;378:113-25.

49. Nakagawa K, Garon EB, Seto T, et al. Ramucirumab plus erlotinib in patients with untreated, EGFRmutated, advanced non-small-cell lung cancer (RELAY): a randomised, double-blind, placebo-controlled, phase 3 trial. Lancet Oncol 2019;20:1655-69.

50. Yamamoto N, Seto T, Nishio M, et al. Erlotinib plus bevacizumab vs erlotinib monotherapy as first-line treatment for advanced EGFR mutation-positive nonsquamous non-small-cell lung cancer: Survival follow-up results of the randomized JO25567 study. Lung Cancer 2021;151:20-4.

51. Ito K, Morise M, Wakuda K, et al. A multicenter cohort study of osimertinib compared with afatinib as firstline treatment for EGFR-mutated non-small-cell lung cancer from practical dataset: CJLSG1903. ESMO Open 2021;6:100115.

52. Kim T, Jang TW, Choi CM, et al. Sequential treatment of afatinib and osimertinib or other regimens in patients with advanced non-small-cell lung cancer harboring EGFR mutations: Results from a real-world study in South Korea. Cancer Med 2021;10:5809-22. 


\section{Supplementary}

Table S1 Treatment outcomes and objective response rate in patients with de novo T790M mutation ( $\mathrm{n}=8)$

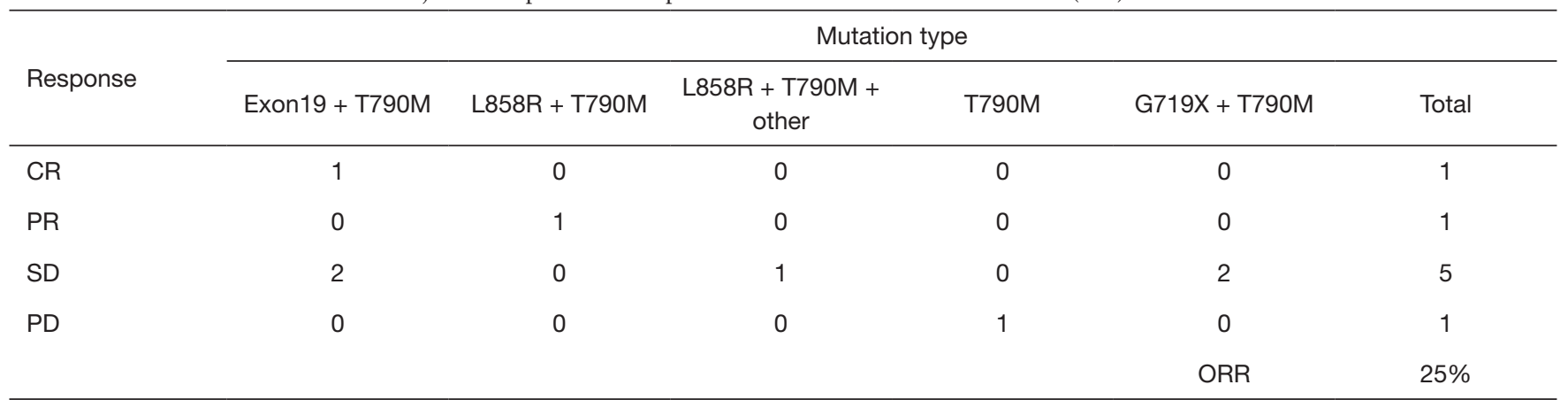

CR, complete response; PR, partial response; SD, stable disease; PD, progressive disease; ORR, overall response rate.

Table S2 EGFR mutation types identified at initial biopsy and rebiopsy, among patients with repeated biopsies $(\mathrm{n}=57)$

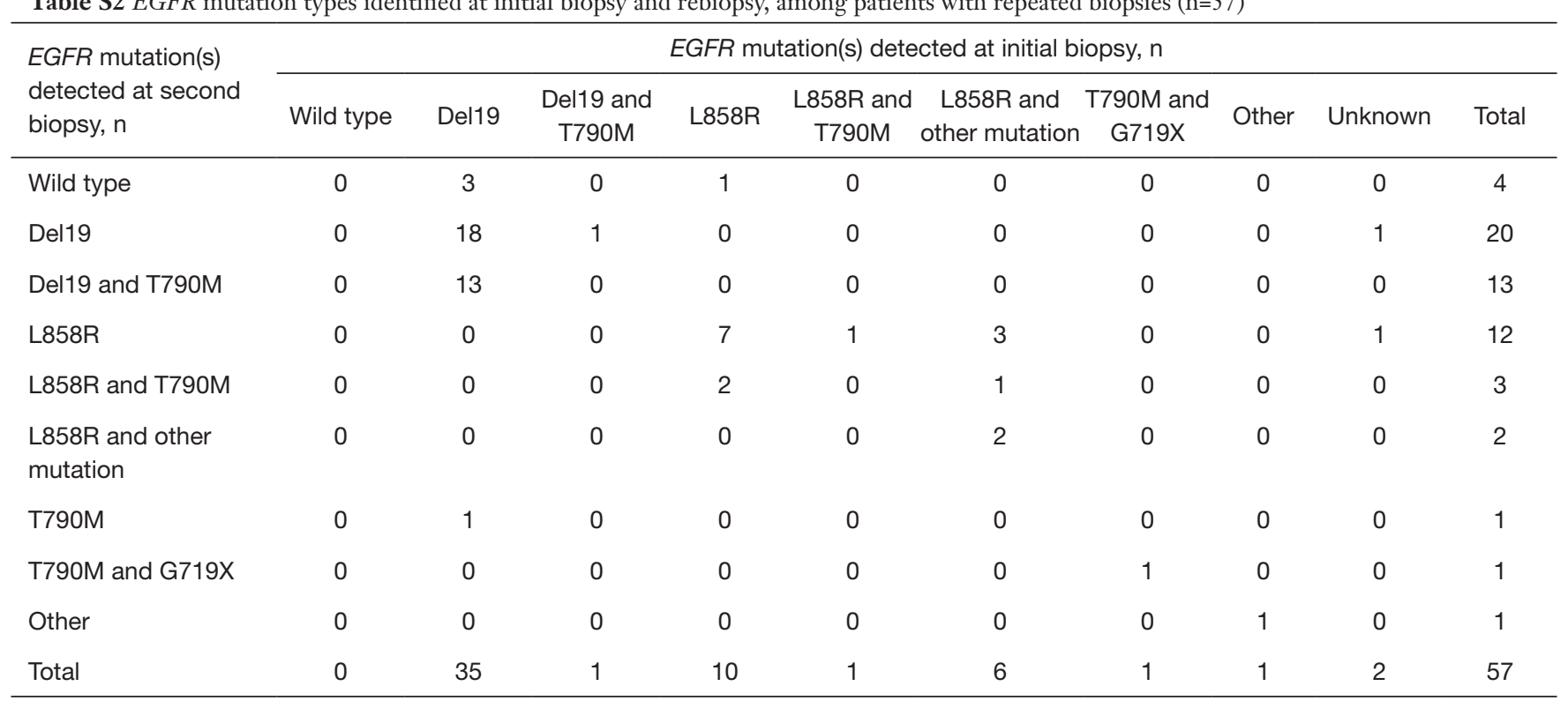

EGFR, epidermal growth factor receptor. 
Table S3 Subsequent treatments after progression on first-line afatinib ( $\mathrm{n}=138)$

\begin{tabular}{lc}
\hline Treatment & Patients, $\mathrm{n}(\%)$ \\
\hline Pemetrexed & $65(47.1)$ \\
Osimertinib & $21(15.2)$ \\
Gemcitabine & $16(11.6)$ \\
Cisplatin & $7(5.1)$ \\
Olmutinib & $6(4.3)$ \\
Gefitinib & $4(2.9)$ \\
Afatinib & $3(2.2)$ \\
Nivolumab & $2(1.4)$ \\
Etoposide & $1(0.7)$ \\
Crizotinib & $1(0.7)$ \\
Other & $12(8.7)$ \\
\hline
\end{tabular}

